\title{
"Not clinically indicated": patients' interests or resource allocation?
}

\author{
Tony Hope, David Sprigings, Roger Crisp
}

The decision that a particular intervention is not clinically indicated may conceal two quite different ethical assumptions. The first assumption is that the intervention is not of overall benefit to this patient. The second is that limited resources should not be used for this patient. These issues are discussed with reference to cardiac surgery in elderly patients with reference to the main theories of allocation: QALYs, needs theories, the sanctity of life theory, the lottery theory, and market forces.

A report from the Royal College of Physicians recommended that elderly patients should have better access to cardiological services, including coronary angioplasty and cardiac surgery. ${ }^{1}$ It also noted, however, that the facilities presently available are inadequate to provide for the patients of all ages who could benefit from these procedures.

It is clear that some elderly patients can benefit from surgery that may previously have been denied on the grounds of age alone. Patients in their 80s now constitute $3.5 \%$ of those undergoing coronary artery bypass grafting at the Mayo Clinic; $79 \%$ of 115 survivors were free of angina after a mean period of 29 months. ${ }^{2}$ The risks of surgery are undoubtedly higher in patients of this age--in two series the hospital mortality was around $10 \%$ and the incidence of postoperative stroke was $4 \% .^{2} 3$

An increased use of angioplasty may limit the number of elderly patients with coronary disease who need bypass grafting for refactory angina, but there is no effective alternative to surgery for the large number of patients in their $70 \mathrm{~s}$ and 80 s with symptomatic aortic stenosis. When stenosis is the cause of severe symptoms, the prognosis without valve replacement is worse than that of many cancers, with a three year mortality around $75 \%{ }^{45}$ Balloon valvoplasty offers only short term palliation." In published series of patients aged 80 years and over undergoing aortic valve replacement ${ }^{7-13}$ the operative mortality was around $15 \%$ (compared with around $4 \%$ for patients under $70^{14-16}$ ). By three to five years after surgery the actuarial survival rate exceeded that of a control population. ${ }^{1013}$ This enhanced survival may reflect the fact that patients referred for surgery were highly selected, and an important limitation of these data is that the selection criteria were not explicit.

\section{Two different points to consider}

For many elderly patients it will be decided that cardiac surgery is not clinically indicated. But the use of the phrase "not clinically indicated" often conceals and confounds two quite different points. The first point is that the operation is not of overall benefit to the patient-for example, the risk of death during the operation outweighs the likely benefit of the operation for the patient. The second is that it is not the right allocation of available resources to use them for this

patient. Both these statements have important ethical dimensions, and they require separate analysis.

In general, where the patient's welfare is the crucial issue the patient should judge. This is a central value in a liberal society. The role of the doctor is to give as accurate and helpful information as is possible to enable the patient to come to a decision.

Even though a patient aged 80 years will usually face a higher operative mortality and a shorter expectation of life than a patient aged 40 years, it does not follow that surgery is not worthwhile for the 80 year old. Paradoxically, the older person might be willing to take a higher risk of death during surgery than a younger person. Indeed surgery, offering, in simplified terms, either a quick death or good health, may be particularly attractive to the old.

Some people aged 80 would not consider major surgery worthwhile because their life is near to close, but others would judge quite differently. If our interest is what is of benefit to the individual patient we must take these differences into account, and in general that means allowing the patient to decide.

\section{Carrying out surgery on an old person is the wrong} allocation of resources

Old people might be denied surgery on the grounds that the available resources are better spent on younger people. But what ethical principles should guide the allocation of resources? We shall briefly discuss some of the main theories of allocation that have been suggested and examine their implications for elderly people with aortic stenosis.

QALYS

Quality adjusted life years (QALYs) form the core of the most thoroughly articulated theory of allocation in health care. On this theory one year of healthy life is taken to be worth 1 . A year of unhealthy life is considered to be worth less than 1: the value is lower if the quality of life of the unhealthy person is worse. A beneficial health care activity is one that generates a positive number of QALYs, and an efficient health care activity is one for which the cost per QALY is low. QALYs are, in effect, units of welfare. A given budget will buy the maximum amount of QALYs if resources are spent on those aspects of care with the least cost per QALY. In this way welfare is maximised.

The application of QALY theory would result in old

Correspondence to:

Dr Hope. 
people having less chance of cardiac surgery than younger people for two main reasons: firstly, the operation is likely to have a higher mortality and morbidity for older people; secondly, older people have in general a shorter life expectancy and therefore fewer life years to gain from the operation.

The main criticisms of QALYs focus on two central points: firstly, that QALYs are unfair because they do not take into account who gains the QALYs; secondly, that "welfare" is not the only value to be put into the equation. Critics have argued that QALY theory is attractive as long as we are considering one person who is weighing up the likely outcomes with different treatments. It is eminently reasonable for an individual to choose the treatment that is likely to generate the most QALYs. But applying QALYs to the allocation of resources is quite different because it involves a choice between the welfares of different people. Thus, for example, those with mental handicap would obtain fewer resources because one year of mentally handicapped life would rate as lower in quality than one year of normal life. Similarly, people with physical handicap affecting the quality of life would have less claim on resources. This would result in those already unfortunate in having one handicap then being less entitled to further medical care. ${ }^{17}$

The fact that old people would lose out with QALY theory has been given as a further example of injustice. The reverse has, however, also been argued: that QALY theory does not discriminate enough against old people. This argument, which has been called "the fair innings argument," was summarised by Lockwood: "To treat the older person, letting the younger person die, would thus be inherently inequitable in terms of life lived: the younger person would get no more years than the relatively few he has already had, whereas the older person, who has already had more than the younger person, will get several years more."18

It follows from this that younger people will normally take preference over older people in the allocation of resources that would postpone death. Is this fair? Do we not all face the same loss, namely death? And do we not all have the same right to be saved? This raises the fundamental issue of how, ultimately, the value of life is to be determined. Harris has argued that the value of life can only sensibly be taken to be that value that those alive place on their lives. ${ }^{19}$

To avoid some of these difficulties with QALYs, Nord has recently suggested the "saved young life equivalent" (SAVE). ${ }^{20}$ Instead of requiring a figure to be placed on quality of life, the SAVE approach requires a direct comparison to be made between the

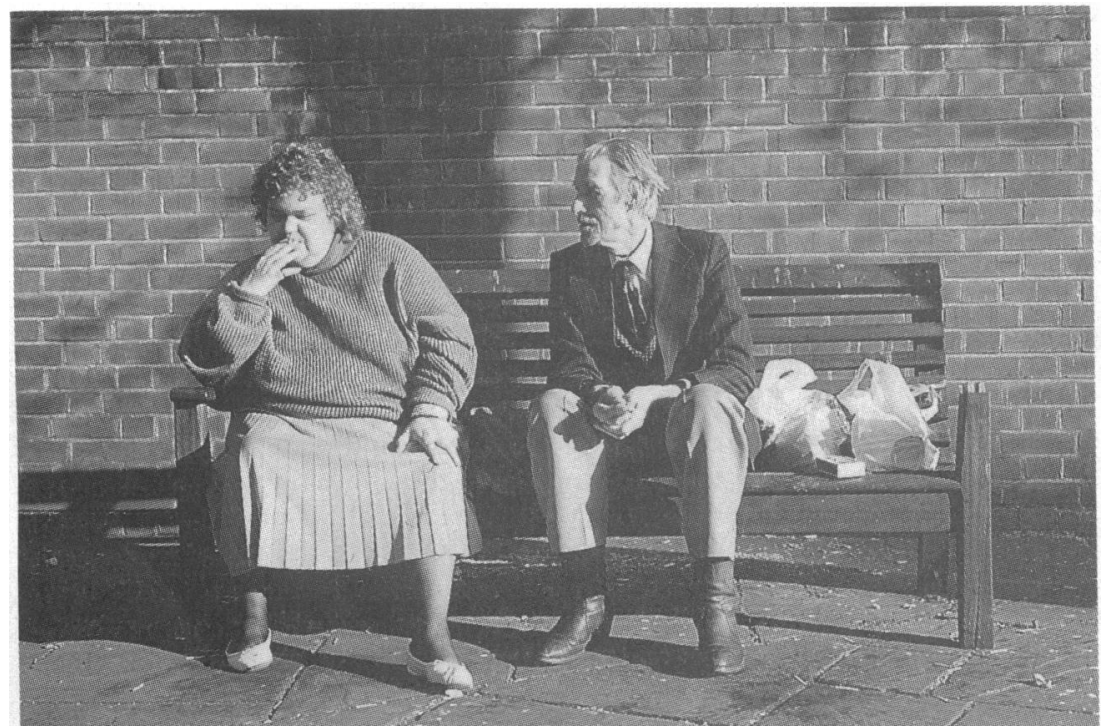

Who will be allocated to cardiac surgery and the chance of a longer life-and who will decide? value of a given intervention (for example, valve replacement in an 80 year old with severe aortic stenosis) and saving the life of a young person, restoring him or her to full health. Any particular evaluator is free, therefore, to rate a treatment for an 80 year old as equally valuable as the equivalent treatment in a 20 year old, or as less valuable, or as more valuable. The SAVE approach gives a way of obtaining the views of a population sample. However, it does not help individual evaluators in deciding on what basis to make their evaluations.

\section{NEEDS THEORIES}

Needs theories arise from the second major criticism of QALY theory: that "welfare" is not the only value. A distinction is drawn between needs and benefits. In allocating resources, needs should be met before benefits.

This theory requires an account to be given of this central distinction. There may be clear cut cases, but there is likely to be a large area where it is unclear whether something is a need or a benefit. Furthermore, the theory is unlikely to be comprehensive. If the total resources are insufficient to meet all needs then how does one choose the needs that should take precedence? And if there are sufficient resources to meet all needs how does one choose which benefits should be funded? It is unclear whether aortic valve replacement, for example, should be classified as a need or a benefit. If replacement is a need it will in general be such for old and young alike, and similarly if it is classified as a benefit. Thus needs theories are likely to share resources equally between young and old. If aortic valve replacement were classified as a need and not simply a benefit, then needs theories, if implemented, might lead to an increased total budget for such surgery to meet the needs of old people with aortic stenosis.

"SANCTITY OF LIFE" THEORY

This theory states that, above all, life must be saved. It is a type of needs theory in which the most important need is to save life. It suffers therefore from the same problems as all needs theories. A further difficulty is that it would apparently require us to put enormous resources towards trivial increases in length of life. Indeed, the whole idea of "saving life" is rejected by some philosophers and replaced by that of "postponing death." It does not seem, in general, valuable to postpone death by a few hours at enormous cost. In the context of valve replacement in old people, the sanctity of life theory would give high priority to a person of any age who is in imminent danger of dying. In other situations it gives no guidance.

\section{THE LOTTERY THEORY}

The lottery theory is a reaction to the perceived injustices of QALY theory. ${ }^{21}$ Where QALY theory concentrates on welfare and ignores justice, the lottery theory concentrates on justice and ignores welfare. It originates from considering, for example, the situation where an older and a younger person would benefit equally from treatment but resources allow only one to be treated. Rejecting the QALY calculation, Harris suggests that since there is no rational way of choosing between the two people the way closest to being just is to choose randomly. Hence the lottery. Thus, an 80 year old and a 40 year old should have an equal chance of being offered cardiac surgery in equivalent circumstances. Many people believe that a lottery is no more just than any other way of choosing-perhaps less so than many other ways. But even if it is just, it does not seem to be comprehensive. It may give a method for allocating resources in a situation like that described, but it is quite unclear how it could be used to allocate resources in general. 
MARKET FORCES

Market forces are part of a vision of a health care system in which individuals buy the care they can afford. With this view, if the 80 year old or the 40 year old can pay for the surgery then it is offered. Otherwise it is not available. This way of allocating resources faces the problems of justice in the same way as the QALY view, but immensely increased. In effect the distribution and quality of health care will be entirely on the basis of personal wealth.

\section{Conclusion}

Doctors may feel that in many cases surgery is not clinically indicated. The word "clinically" here can be dangerously misleading, for the decision being made has a major ethical component. It is as important to clarify the ethical judgments being made as it is to understand the basis for technical decisions.

1 Royal College of Physicians Working Group. Cardiological intervention in elderly patients. I $R$ Coll Physicians Lond 1991;25:197-205.

2 Mullany CJ, Darling GE, Pluth JR, Orszulak TA, Schaff HV, Ilstrup DM, et al. Early and late results after isolated coronary artery bypass surgery in 159 patients aged 80 years and older. Circulation 1990;82(suppl 4):229-36.

3 Weintraub WS, Craver JM, Cohen CL, Jones EL, Guyton RA. Influence of age on results of coronary artery surgery. Circulation 1991;84(suppl 3): age on $226-35$.

4 Turina J, Hess O, Sepulcri F, Krayenbuehl HP. Spontaneous course of aortic valve disease. Eur Hear $\mathcal{F}$ 1987;8:471-83.

5 O'Keefe JH Jr, Vlietstra RE, Bailey KR, Holmes DR Jr. Natural history of candidates for balloon aortic valvuloplasty. Mayo Clin Proc 1987;62:986-91.
6 Kuntz RE, Tosteson ANA, Berman AD, Goldman L, Gordon PC, Leonard BM, et al. Predictors of event-free survival after balloon aortic valvuloplasty. N Engl f Med 1991;325:17-23.

7 Rich MW, Sandza JG, Kleiger RE, Connors JP. Cardiac operations in patients over 80 years of age. 7 Thorac Cardiovasc Surg 1985;90:56-60.

8 Tsai TP, Matloff JM, Gray RJ, Chaux A, Kass RM, Lee ME, et al. Cardiac surgery in the octogenarian. $f$ Thorac Cardiovasc Surg 1986;91:924-8.

Edmunds LH Jr, Stephenson LW, Edie RN, Ratcliffe MB. Open-hear surgery in octogenarians. $N$ Engl $f$ Med 1988;319:131-6.

10 Levinson JR, Akins CW, Buckley MJ, Newell JB, Palacios IF, Block PC, et al Octogenarians with aortic stenosis: outcome after aortic valve replacement. Circulation 1989;80(suppl 1):49-56.

11 Fiore AC, Naunheim KS, Bamer HB, Pennington DG, McBride LR, Kaiser GC, et al. Valve replacement in the octogenarian. Ann Thorac Surg 1989;48:104-8.

12 Freeman WK, Schaff HV, O'Brien PC, Orszulak TA, Naessens JM, Tajik AJ. Cardiac surgery in the octogenarian: perioperative outcome and clinical follow-up. I Am Coll Cardiol 1991;18:29-35.

13 Culliford AT, Galloway AC, Colvin SB, Grossi EA, Baumann FG, Espositi R, et al. Aortic valve replacement for aortic stenosis in persons aged 80 years and over. Am f Cardiol 1991;67:1256-60.

14 Magovern JA, Pennock JL, Campbell DB, Pae WE, Bartholomew M, Pierce WS, et al. Aortic valve replacement and combined aortic valve replacement and coronary artery bypass grafting: predicting high risk groups. $\int \mathrm{Am} \mathrm{Coll}$ Cardiol 1987;9:38-43.

15 Craver JM, Weintraub WS, Jones EL, Guyton RA, Hatchet CR Jr. Predictor of mortality, complications, and length of stay in aortic valve replacemen for aortic stenosis. Circulation 1988;78(suppl 1):85-90.

16 Fremes SE, Goldman BS, Ivanov J, Weisel RD, David TE, Salerno T Valvular surgery in the elderly. Circulation 1989;80(suppl 1):77-90.

17 Harris J. QAL Yfying the value of life. 3 Med Ethics 1987;13:117-23.

18 Lockwood M. Quality of life and resource allocation. In: Bell JM, Mendus S, eds. Philosophy and medical welfare. Cambridge: Cambridge University Press, 1988:33-5.

19 Harris J. The value of life. London: Routledge, 1985.

20 Nord E. An alternative to QALYs: the saved young life equivalent (SAVE) BMF 1992;305:875-7.

21 Broome J. Good, fairness and QALYs. In: Bell JM, Mendus S, eds. Philosophy and medical welfare. Cambridge: Cambridge University Press, 1988:57-73.

(Accepted 17 November 1992)

\section{Department of \\ Epidemiology and Public \\ Health, The Medical \\ School, University of \\ Newcastle upon Tyne, \\ Newcastle upon Tyne \\ NE2 4HH \\ Rajinder S Bhopal, professor of epidemiology and public health}

BMF 1993;306:381-2

\section{Public health medicine and purchasing health care}

\section{Rajinder S Bhopal}

Public health medicine is a goal driven medical specialty. Although the tasks of public health doctors are always changing, their goal remains firm: improving the health of the population. As the route to this goal is neither obvious nor agreed and differs between places and eras continuous debate is essential and occasional heresy welcome. Thus Whitty and Jones argued recently that public health medicine embraces the purchasing role at its peril.' ${ }^{\prime}$ They achieved their main aim-debate ${ }^{2}$-but I now examine whether their analysis was correct.

\section{Health care and health}

Underpinning Whitty and Jones's argument was the belief that health care only minimally influences health. This owes much to McKeown and Lowe who suggested that socioeconomic and environmental circumstances are the prime determinants of longevity. If the goals of public health medicine are health promotion and the prevention of ill health, warn Whitty and Jones, then the specialty is in danger of veering off course in pursuit of the purchasing function, which "is likely to be ineffective in improving the population's health and may even be in direct conflict with this role."1

Whitty and Jones's analysis stands or falls on the meaning of health, whether health services have an impact on health, and on the central functions of public health medicine. I examine these variables below.

MEANING OF "HEALTH"

The meaning of the term health is not self evident. Health is usually described as either the absence of disease or infirmity, the efficient functioning of human beings, or a state of wellbeing. The World Health Organisation's definition that health is a state of complete physical, mental, and social wellbeing and not merely the absence of disease or infirmity redresses the medically biased emphasis on disease or infirmity. But disease and infirmity cannot be ignored.

\section{IMPACT OF HEALTH SERVICES}

The NHS, through its preventive, curative, and rehabilitative services, reduces premature death and disability $^{67}$ and improves people's ability to function. Health services enhance wellbeing by providing care, reducing distress and pain, and issuing a diagnosis or prognosis which may provide reassurance or comfort. The benefits of health services are not well quantified and may never be quantified, particularly in the face of scientific, technological, and organisational change. Absence of evidence is not synonymous with evidence of ineffectiveness.

Compared with social, economic, lifestyle, and environmental factors health services have a limited impact on life expectancy and health status. Nevertheless, the findings of McKeown and Lowe 4 should not be interpreted as denying the role of health services in improving health. Instead, they should be taken as emphasising that the determinants of health-particularly as they affect life expectancy and the incidence of disease-are mainly environmental. McKeown and Lowe arranged the main influences responsible for falling mortality in descending order of importance as a rising standard of living, improved hygiene, and specific preventive and therapeutic measures. ${ }^{4}$

McKeown's analysis of life expectancy and (mainly infectious) diseases in the eighteenth, nineteenth, and early twentieth centuries requires updating. Szreter's counterargument - that the fall in mortality in the nineteenth century was deeply influenced by "human agency in the form of politically negotiated expansion 